\title{
Protótipo de Aplicativo para cuidados com a pele: SkinKarin
}

\author{
Skin care app prototype: SkinKarin
}

Júnior Antônio Beluzzo, Júlia de Brito Petite Amaral, Nycole Taymara Stanichuk Pedra Hume, Alexsandro Stumpf

experiência do usuário, interface, usabilidade, skincare

O presente artigo trata do processo de criação de um protótipo de interface digital para auxiliar na rotina de cuidados com a pele (skincare), a partir da observação do crescimento no interesse pelo tema. O protótipo foi projetado baseado na proposta metodológica de Garrett, com ferramentas e técnicas para planejar os planos de experiência do usuário. Um teste de usabilidade foi incluído e as experiências dos usuários foram classificadas, embasadas em seus relatos. Os resultados alcançados foram majoritariamente positivos, existindo a possibilidade de corrigir falhas e prosseguir com o desenvolvimento do aplicativo. Finalmente, constatou-se que metodologias baseadas em Garrett, que sugerem ferramentas e técnicas, podem aprimorar os processos.

user experience, interface, usability, skin care

This article deals with the process of creating a prototype digital interface to assist in the routine of skin care, based on the observation of the growing interest in the topic. The prototype was designed based on Garrett's methodological proposal, with tools and techniques to plan user experience planes. A usability test was included and the users' experiences were classified, based on their reports. The results achieved were mostly positive, with the possibility of correcting flaws and continuing with the development of the app. Finally, it was found that methodologies based on Garrett, which suggests tools and techniques, can improve the processes.

\section{Introdução}

Em março de 2020, o diretor-geral da Organização Mundial da Saúde (OMS) informou que a COVID-19 passou a ser considerada como uma pandemia (OPAS, 2020). Com isso, foi possível observar mudanças de comportamento nos brasileiros, inclusive no que diz respeito à relação homem-máquina. Houve, durante a pandemia, um aumento médio de $1 \mathrm{~h} 30$ em relação ao tempo de uso anterior de computadores ou tablets. Entre adultos jovens (18-29 anos), este aumento foi de quase $3 \mathrm{~h}$ (Malta et. al, 2020).

De modo similar, houve também o crescimento no tempo de uso de aplicativos móveis. A nível global, o tempo mensal gasto em aplicativos móveis aumentou $40 \%$ no segundo trimestre de 2020, em relação ao segundo trimestre de 2019. (Kristianto, 2020). Curitiba | Brazil | 2021 
Buscando pelo termo "skincare" no Google Trends ${ }^{1}$, identificou-se crescimento relativo de $588,23 \%$ no interesse pelo termo, ao comparar a segunda semana de outubro de $2019 \mathrm{com}$ a segunda semana de outubro de 2020 , quando atingiu o pico. Os filtros utilizados foram de localização (Brasil) e período personalizado (01/01/2019 a 31/12/2020).

Conforme dados extraídos da pesquisa realizada pela agência de inteligência de mercado mundial Mintel, $63 \%$ dos brasileiros afirmam que estão dando maior prioridade a sua saúde mental e $48 \%$ concordam que usar produtos de beleza e cuidados pessoais melhora a autoestima (Globo, 2020).

Tendo em vista os fatores anteriormente citados, percebeu-se a oportunidade de desenvolver um aplicativo com foco em skincare. Consequentemente, o presente trabalho tem por objetivo apresentar as etapas resultantes da aplicação da metodologia no design do protótipo de interface digital do aplicativo idealizado, e considerações sobre a eficácia desta.

A elaboração do projeto teve base na proposta metodológica de Garrett (2011). Todas as etapas de desenvolvimento levaram em consideração os 5 planos de experiência do usuário: estratégia; escopo; estrutura; esqueleto e; superfície.

\section{Os 5 planos de experiência do usuário}

De acordo com Garret (2011) a experiência do usuário é resultado de um conjunto de decisões sobre a aparência e a configuração de uma interface, podendo ser divididas em 5 planos para melhor compreensão destas decisões. Estes são compostos - do mais abstrato para o mais concreto - em estratégia, escopo, estrutura, esqueleto e superfície.

\section{Plano 1 - Estratégia}

Nesta etapa estão os objetivos do produto e as necessidades do usuário. Segundo Garrett (2011), neste plano não devem estar apenas as expectativas dos administradores do site, mas também as dos usuários. Em síntese, busca-se solucionar um problema do usuário através de um produto ou serviço ofertado. Para este plano o grupo tomou decisões referentes ao nome do produto, características, problemas a solucionar, público-alvo e formato a ser desenvolvido.

O nome do aplicativo foi criado a partir do jogo de palavras entre "skincare" e "Karin". A ideia surgiu conectada à criação de uma mascote, chamada Karin, para representar o aplicativo. Como principal característica, definiu-se a gratuidade e a disponibilização do conteúdo em português, para auxiliar na rotina de cuidados com a pele. Assim, busca-se solucionar a dificuldade em acompanhar os resultados obtidos nos cuidados com a pele e a criação de hábitos de rotina.

Como público-alvo, definiu-se brasileiros, jovens adultos, com renda de 1 a 6 salários mínimos. Espera-se que este público possa encontrar senso de comunidade e obtenha uma pele mais saudável, conforme suas próprias expectativas.

\footnotetext{
${ }^{1}$ Resultado de pesquisa disponível em: https://bityli.com/zJWTi. Acesso em: 11 mai. 2021.
} 
Entende-se que o formato de aplicativo seja o ideal para o desenvolvimento do projeto, devido ao número crescente de pessoas que possuem smartphone. Posteriormente, um website pode dar suporte para a captação de novos usuários.

\section{Plano 2 - Escopo}

No escopo definem-se como serão os recursos e funcionalidades que compõem o produto. Buscar inspiração em concorrentes, analisar recursos que solucionem dificuldades e até mesmo a forma como estes lidam com os mesmos problemas que enfrentamos são algumas maneiras para pensar em novas soluções (Garrett, 2011).

Portanto, a fim de compreender os benefícios e lacunas existentes em aplicativos já existentes, bem como os conteúdos relevantes para o público-alvo, o grupo analisou 4 aplicativos: TroveSkin, Amigos da Pele, SkinCare Routine e SkinSmart. Assim, uma tabela de benchmarking foi elaborada para avaliação dos mais e menos promissores, atribuindo notas de 0 a 100 para os critérios apresentados na tabela a seguir.

Tabela 1: Benchmarking

\begin{tabular}{lllll}
\hline & Troveskin & $\begin{array}{l}\text { Amigos da } \\
\text { Pele }\end{array}$ & $\begin{array}{l}\text { Skincare } \\
\text { Routine }\end{array}$ & SkinSmart \\
\hline Usabilidade & 70 & 80 & 80 & 70 \\
Funcionalidade & 90 & 50 & 90 & 80 \\
Reviews de & 90 & 78 & 92 & 80 \\
usuários & & & & 80 \\
Aparência & 100 & 40 & 60 & 77,5 \\
Média & 87,5 & 62 & 80,5 & \\
\hline
\end{tabular}

A partir da tabela anterior, tornou-se mais fácil refletir sobre as funcionalidades desejadas. Garret (2011) afirma que, apesar de não haver necessidade de incorporar todos os aspectos, definir claramente as funcionalidades pode evitar confusões posteriores. Portanto, a tabela 2 foi criada como base projetual.

Tabela 2: Especificações de funcionalidades

\begin{tabular}{ll}
\hline Funcionalidade & Descrição \\
\hline Dispositivos atendidos & Android e iOS (app) \\
Cadastro & $\begin{array}{l}\text { Poderá ser feito via botão de integração (Google e Facebook) ou } \\
\text { formulário (sucinto e de rápido preenchimento). }\end{array}$ \\
Detalhamento do & O SkinKarin será gratuito, em português, e proporcionará a troca \\
aplicativo & $\begin{array}{l}\text { de informações sobre skincare entre usuários. Reunirá } \\
\text { informações provenientes de estudos científicos e auxiliará no } \\
\text { dia-a-dia de quem se preocupa com saúde e bem-estar. }\end{array}$
\end{tabular}




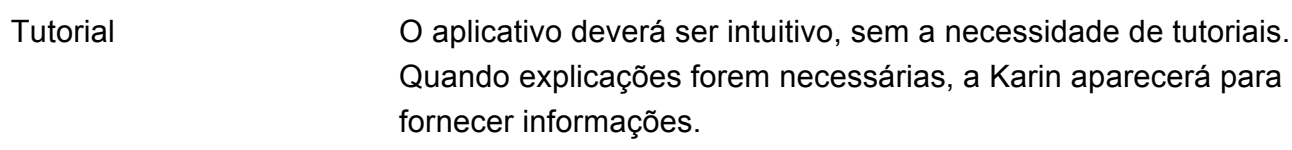

Karin A mascote digital simulará conversas com o usuário, coletando informações necessárias para o funcionamento do aplicativo.

Comunidade Reunirá comentários, postagens, vídeos e trocas de experiências entre usuários.

Ranking Proporcionará a gamificação da experiência através de pontos de experiência, estimulando a continuidade da rotina.

\section{Plano 3 - Estrutura}

Conforme Garret (2011), na estrutura encontram-se informações sobre a origem e o destino dos usuários. Este planejamento influenciará diretamente no resultado final. Como resultado, um mapa de navegação (Figura 1) foi criado para facilitar a identificação dos caminhos a serem percorridos até chegar em determinada tela.

Figura 1: Mapa de navegação

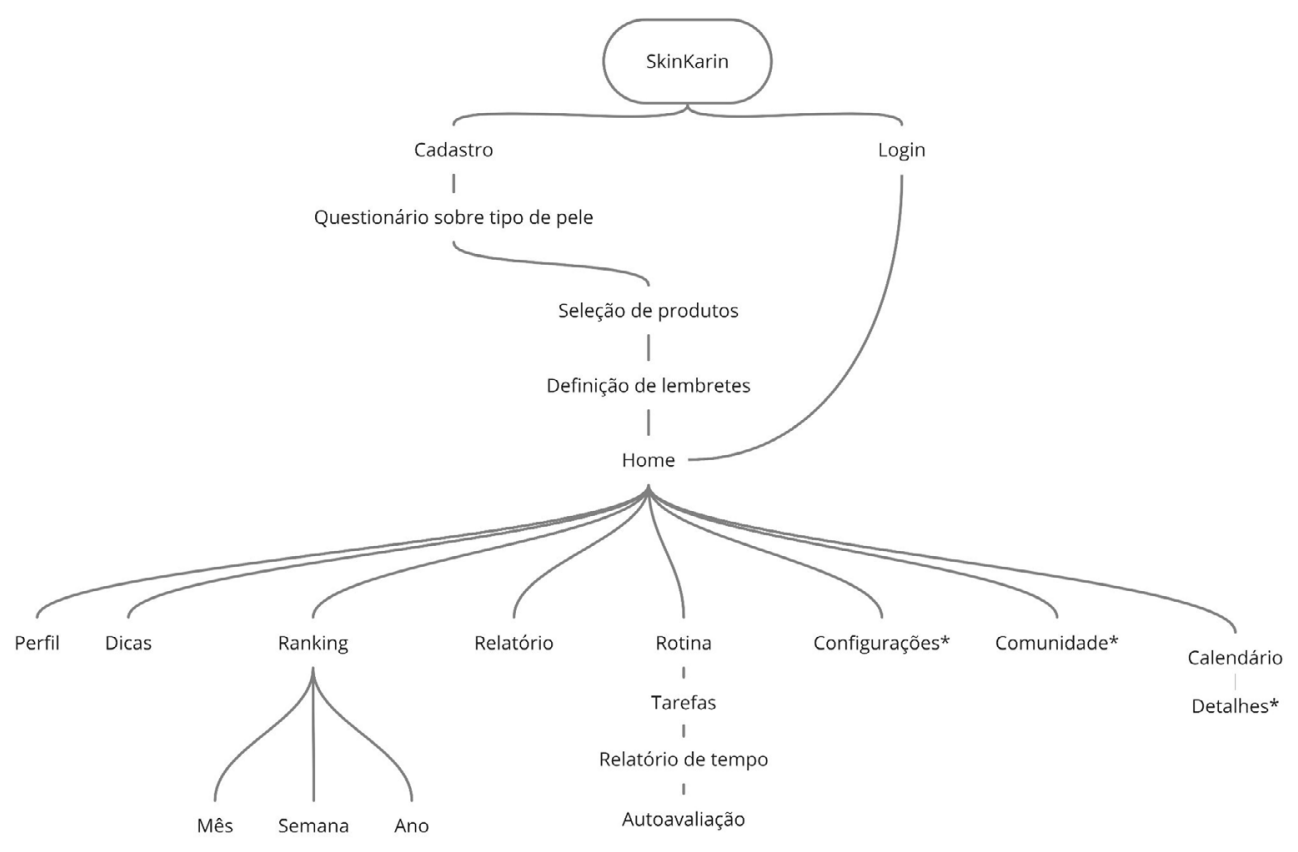

*Não foi possível incluir continuação das listas devido ao tamanho da imagem

\section{Plano 4 - Esqueleto}

No esqueleto, estão as definições de arranjo dos elementos e organização das informações na tela (Garret, 2001). Por isso, utilizou-se o que foi definido anteriormente para a construção de wireframes, facilitando o planejamento das funções e da usabilidade do aplicativo.

Sob a premissa de que muitas informações juntas podem causar desinteresse logo no primeiro uso, houve a preocupação em apresentar poucos elementos e guiar as interações com apelos informais (textos descontraídos e apresentação da mascote Karin). 
Figura 2: Wireframes de login e cadastro

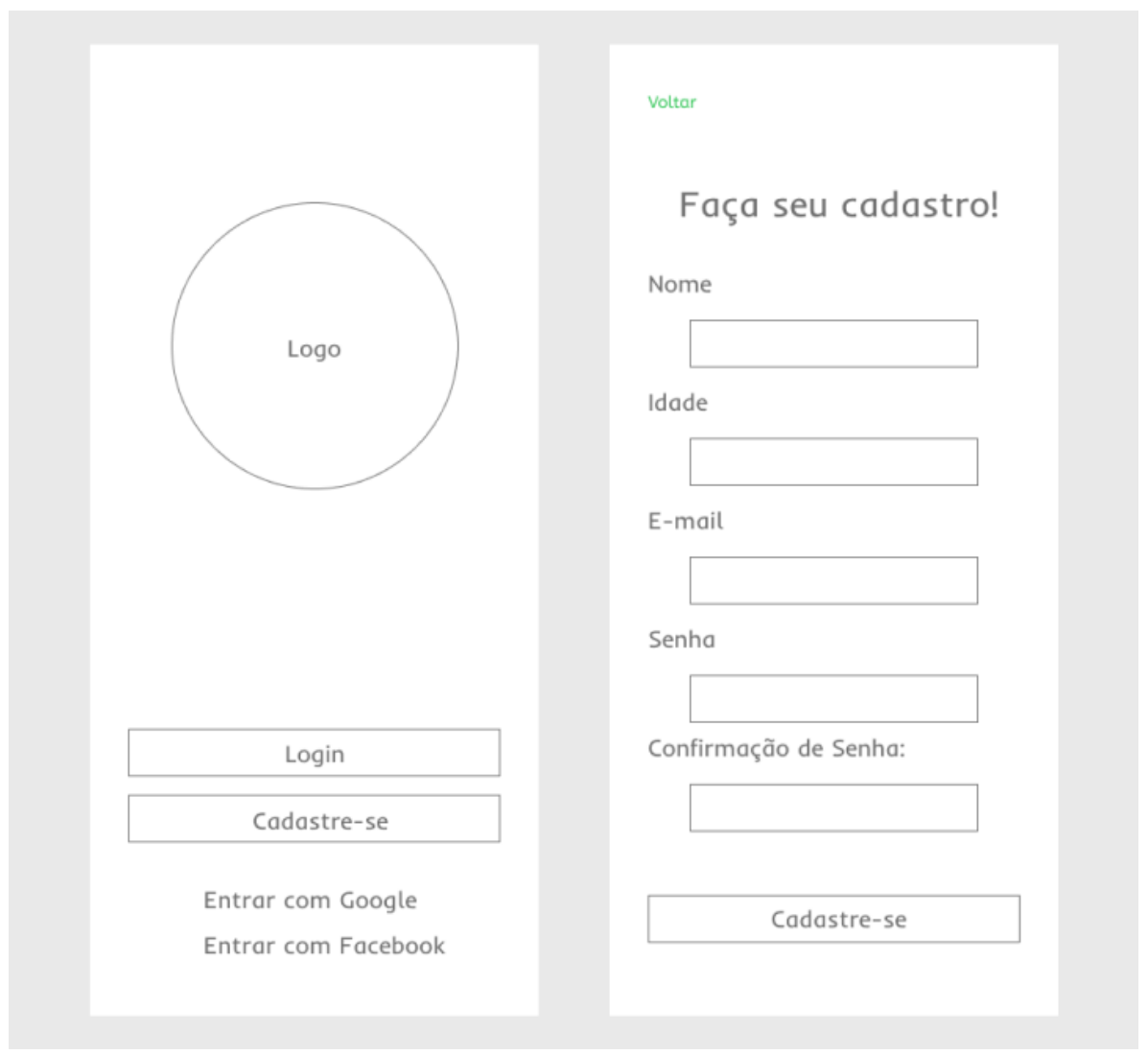

Figura 3: Wireframes de questionário

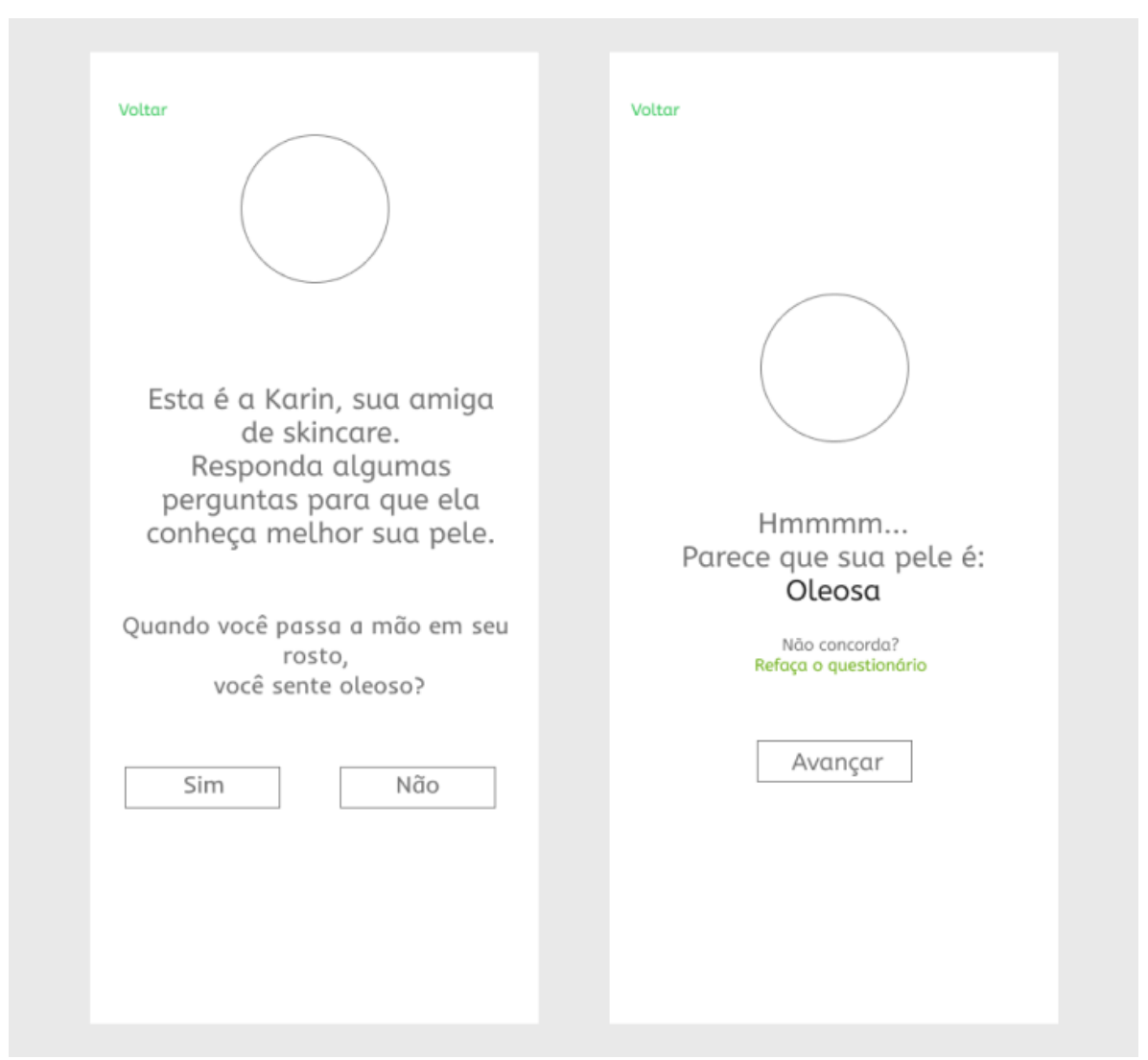


Figura 4: Wireframes de seleção de produtos e definição de lembretes

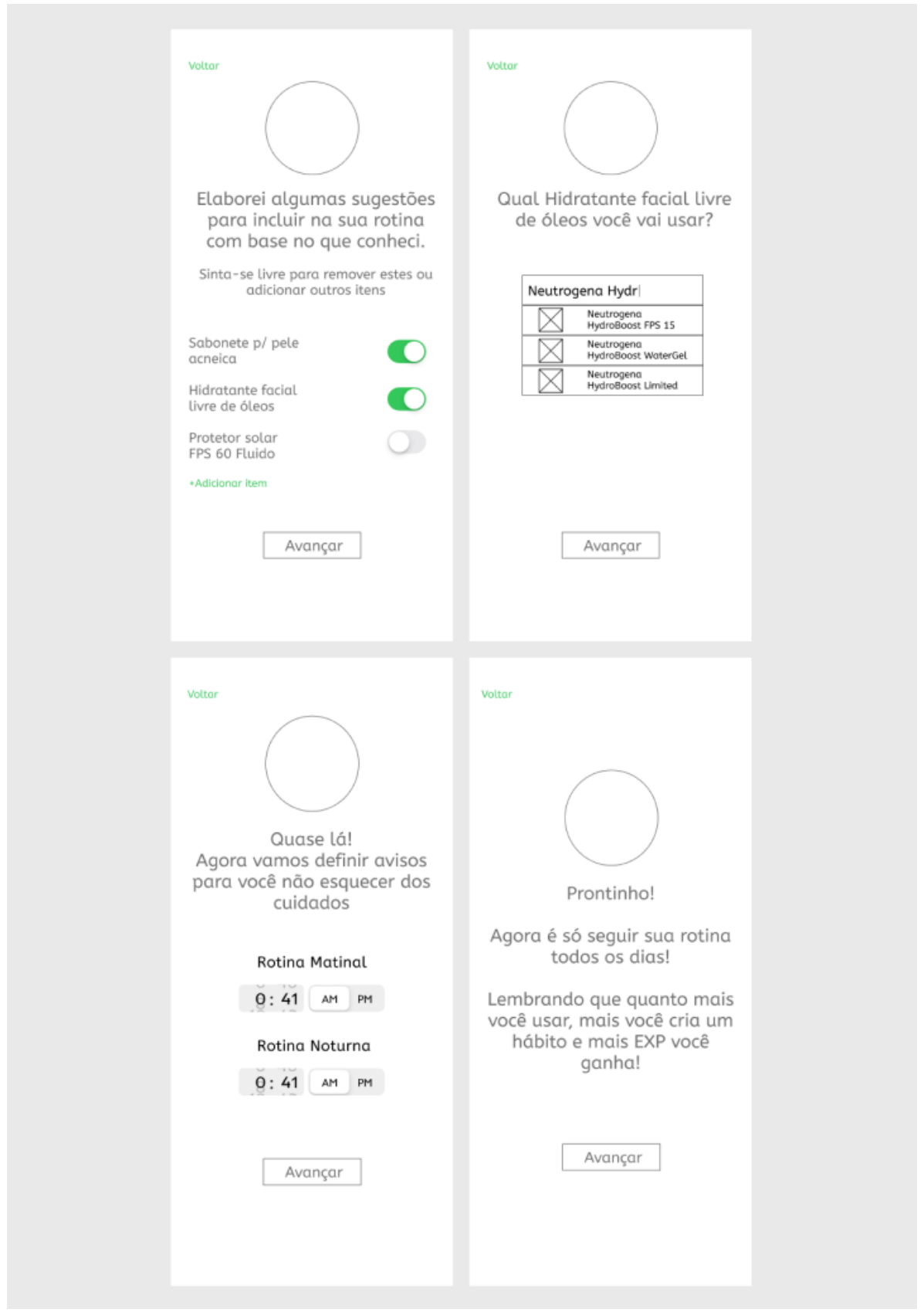

\section{Plano 5 - Superfície}

A etapa de superfície é a mais concreta e próxima do usuário, por isso inclui os aspectos visuais e sensoriais. É onde o conteúdo, funcionalidade e estética operam de forma conjunta. (Garret, 2011). Para esse fim, ocorreu a criação da marca e style guide, escolha de tipografia, grids, iconografia, etc., e prototipação. 
Figura 5: Marca

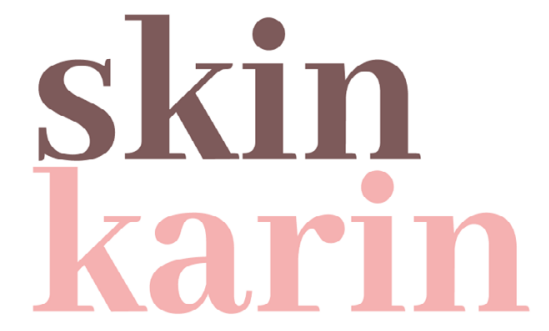

Figura 6: Telas de login e cadastro

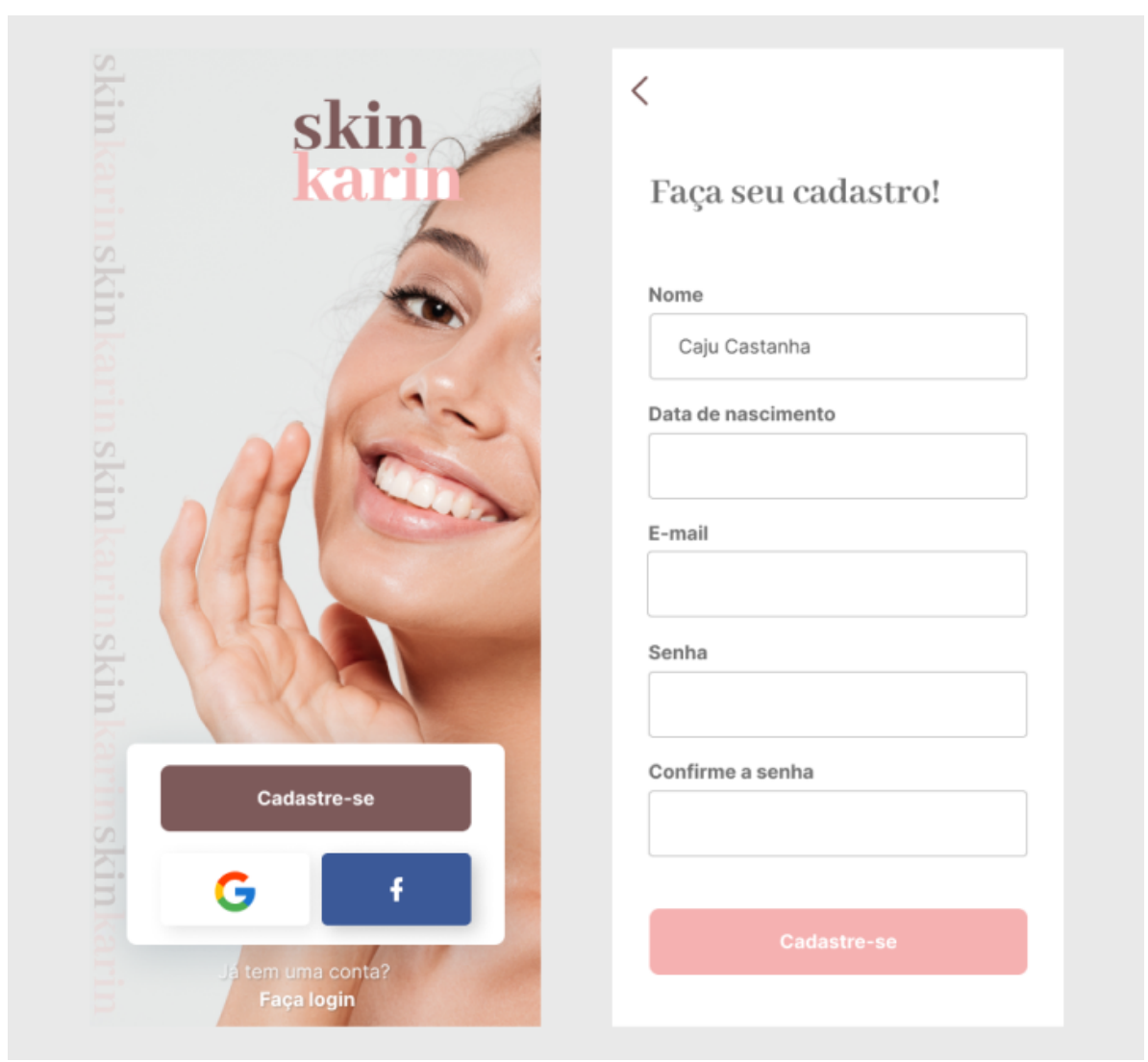


Figura 7: Telas de questionário

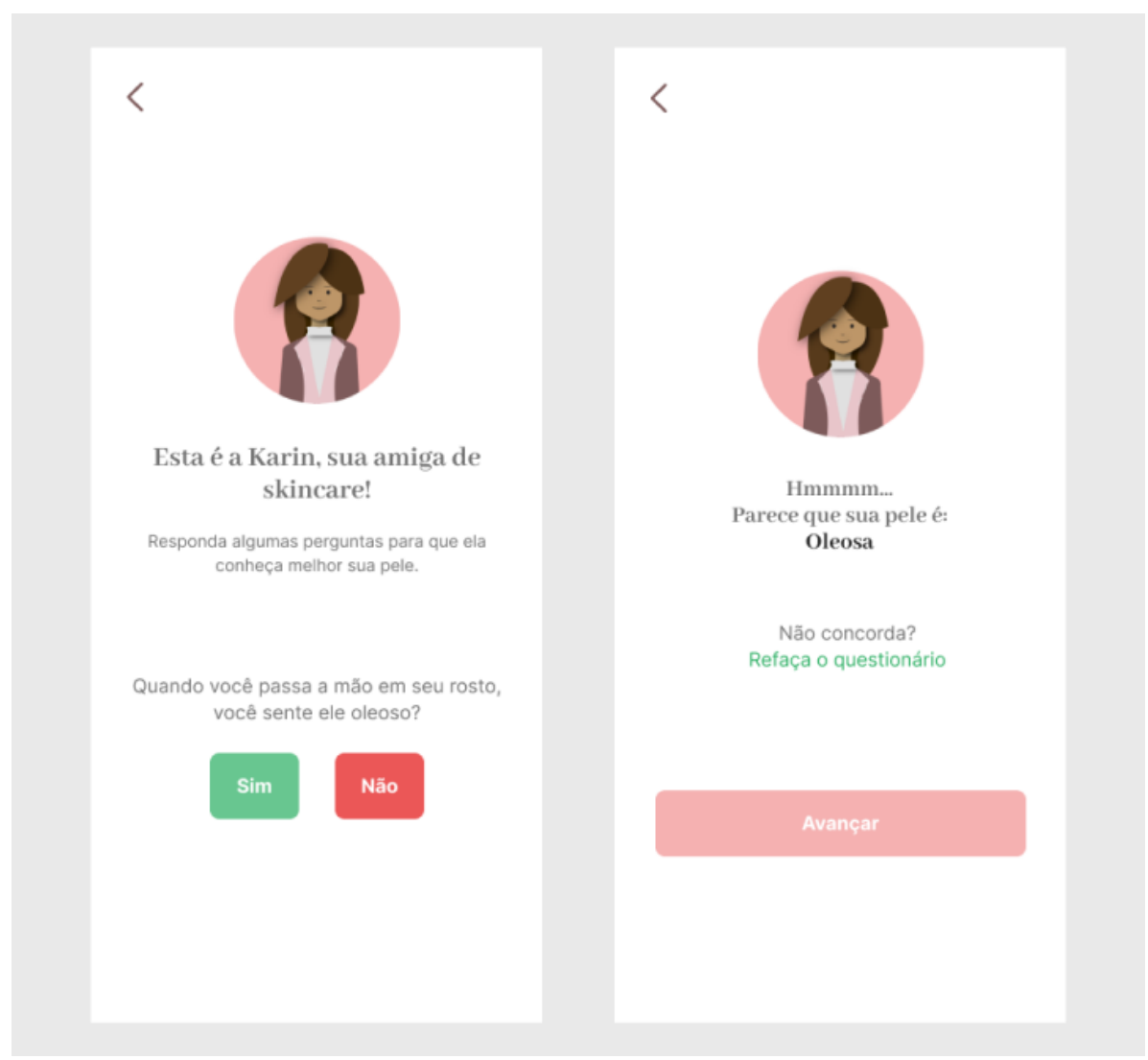


Figura 8: Amostras de outras telas

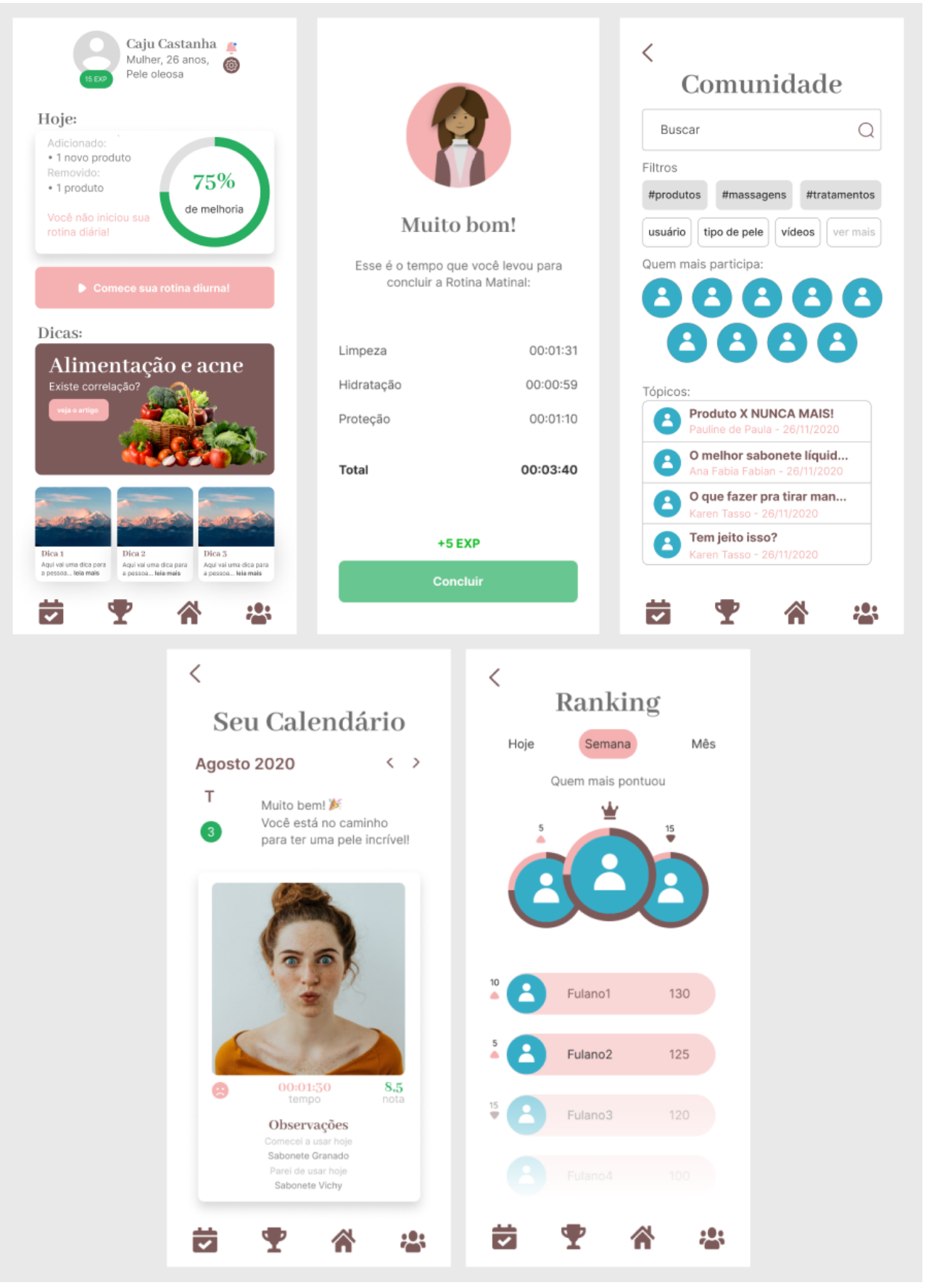

Testes de usabilidade

Enfim, para identificar problemas de usabilidade, falhas no projeto e retroalimentação dos processos, uma etapa de testes foi incluída. Os usuários participantes foram esclarecidos sobre objetivos e propósitos da pesquisa, receberam um link para o protótipo digital e foram solicitados a compartilhar a tela do dispositivo.

Primeiro, cada usuário teve 2 minutos para navegação livre, objetivando a familiarização com a interface. Em seguida, solicitou-se que realizassem 4 tarefas específicas: 
- Cadastrar-se no aplicativo para acessá-lo e abrir a guia comunidade;

- Encontrar a informação sobre o tempo utilizado na rotina de skincare em 3 de agosto;

- Voltar à página inicial e iniciar rotina diária;

- Encerrar sessão (log out).

As queixas, elogios e relatos dos usuários, resultaram na criação da tabela abaixo:

Tabela 3: Classificação das experiências após o teste de usabilidade

\begin{tabular}{ll}
\hline Experiências Desagradáveis & Experiências Agradáveis \\
\hline Não foi possível editar o texto de & Ícones intuitivos; \\
formulários; & Fácil acesso às funcionalidades; \\
Erro na tela de autoavaliação (botão & Rapidez para execução das tarefas; \\
"concluir" e "home" não funcionaram); & Opção de login com Google e Facebook; \\
Poucas perguntas para definir o perfil da & Proposta de acompanhamento da rotina pelo \\
pele do usuário; & calendário; \\
& Interface visualmente agradável; \\
\hline
\end{tabular}

\section{Conclusão}

Acredita-se que seja possível fornecer uma experiência positiva ao usuário com a proposta metodológica utilizada. A etapa de testes com o usuário foi essencial para verificar, corrigir erros e conferir se a interação com a interface acontece facilmente.

Dadas as oportunidades identificadas, observa-se a possibilidade de corrigir falhas e continuar com o desenvolvimento do aplicativo. Contudo, cabe ressaltar que a ausência de funcionalidades que permitissem edição de texto gerou desconforto ao usuário, ainda que o projeto tenha sido concebido como um protótipo digital. Percebe-se que o uso de tecnologias que integrem formulários interativos pode tornar a experiência mais semelhante à realidade.

Ao fim do projeto, acredita-se que a proposta de Garrett seja generalista e, por isso, não foca na apresentação de ferramentas e técnicas que facilitem a equipe a atingir seus objetivos. As metodologias baseadas em Garrett, com finalidades mais específicas, podem ser uma alternativa. Como exemplo de aplicação em outra área, existe a metodologia Interad, focada em ambientes educacionais.

\section{Referências}

Garrett, J. J. (2011). The elements of user experience: user-centered design for the Web and beyond. Berkeley: New Riders.

Globo (08 out. 2020). Skincare: higiene e beleza em alta na pandemia. Disponível em: https://gente.globo.com/skincare-higiene-e-beleza-em-alta-na-pandemia. Acesso em: 11 mai. 2021. 
Kristianto, D. (08 jul. 2020). App Annie. Mobile App Usage Surged 40\% During COVID-19 Pandemic. Disponível em: https://www.appannie.com/en/insights/market-data/mobile-appusage-surged-40-during-covid-19-pandemic/. Acesso em: 29 abr. 2021.

Malta, D. C., Szwarcwald, C. L., Barros, M. B. A., Gomes, C. S., Machado, Í. E., Souza Júnior, P. R. B., Romero, D. E., Lima, M. G., Damacena, G. N., Pina, M. F., Freitas, M. I. F., Werneck, A. O., Silva, D. R. P., Azevedo, L. O., \& Gracie, R. (2020). A pandemia da COVID19 e as mudanças no estilo de vida dos brasileiros adultos: um estudo transversal, 2020. Epidemiologia e Serviços de Saúde, 29. https://doi.org/10.1590/s1679-49742020000400026

Organização Pan-Americana da Saúde (11 mar. 2020). OMS afirma que COVID-19 é agora caracterizada como pandemia. Disponível em: https://www.paho.org/pt/news/11-3-2020who-characterizes-covid-19-pandemic. Acesso em: 11 mai. 2021.

\section{Sobre os autores}

Júnior Antônio Beluzzo, Graduando, Universidade Comunitária da Região de Chapecó, Brasil, juniorbeluzzo@hotmail.com.

Júlia de Brito Petite Amaral, Graduanda, Universidade Comunitária da Região de Chapecó, Brasil, arosetothesky@unochapeco.edu.br.

Nycole Taymara Stanichuk Pedra Hume, Graduanda, Universidade Comunitária da Região de Chapecó, Brasil, nyhume.nycole@gmail.com.

Alexsandro Stumpf, Mestre, Universidade Comunitária da Região de Chapecó, Brasil, alexsandro@unochapeco.edu.br. 